\title{
Effect of an Enteral Diet Containing Medium-Chain Triglyceride on Protein Metabolism in Septic Rats
}

\author{
Harumi Handa, ${ }^{1}$ Tsuneo Mizuguchi, ${ }^{2}$ Naoki Hayashi, ${ }^{1}$ \\ Tsuyoshi NAKAmura, ${ }^{2, *}$ Nobuhiro YAJIMA, ${ }^{2}$ \\ and Yasuyoshi TAKESHITA ${ }^{2}$ \\ ${ }^{1}$ Pharmaceutical Department, Snow Brand Milk Products Co., Ltd., \\ Shinjyuku-ku, Tokyo 160, Japan \\ ${ }^{2}$ Research Institute of Life Science, Snow Brand Milk \\ Products Co., Ltd., Ishibashi-machi, Tochigi 329-05, Japan
}

(Received September 5, 1996)

\begin{abstract}
Summary We studied the effects of an enterally administered diet containing medium-chain triglycerides (MCT) on protein metabolism in septic Wistar rats and compared them with those of a long-chain triglycerides (LCT). The sepsis was induced by cecal ligation and puncture. The rats were divided into two groups. One group was fed a diet containing a MCT and LCT mixture (MCT/LCT), and the other was fed one containing LCT, as $10 \%$ of total energy. The diets also contained protein, dextrin, vitamins, and electrolytes. The experimental diets were via an intraduodenal catheter for 6 days. The MCT/LCT group showed a higher nitrogen balance after 3 days of the feeding and a higher liver protein content compared with the LCT group on the last day. Furthermore, the concentrations of serum total protein and albumin in the MCT/LCT group were higher than those in the LCT group. These results indicate that the enteral diet containing MCT combined with LCT may be advantageous to protein metabolism in septic rats over the diet with LCT alone.
\end{abstract}

Key Words: medium-chain triglycerides, long-chain triglycerides, septic rats, protein metabolism, enteral diet

Sepsis is caused by an influx of microorganisms or their toxins into the bloodstream. As the energy expenditure in septic patients suffering from severe infections such as peritonitis increases up to $160 \%$ of the normal individual [1-3], a typical energy insufficiency often accompanies sepsis. Septic patients therefore

*To whom correspondence should be addressed. 
require a supplement of energy sufficient to compensate for the deficit. Generally fats are a more effective energy source than carbohydrates or proteins because of their high caloric value. However the utilization of fats, in particular long-chain triglycerides (LCT), might be impaired in sepsis $[4,5]$, because the level of carnitine, which is essential for oxidation of LCT, is decreased in blood [6] and tissues [7] in the septic state.

On the other hand, medium-chain triglycerides (MCT) are different from LCT in their metabolism, for MCT can be used as an energy source without carnitine in the liver and other organs [8]. Therefore, MCT may be preferred for septic patients over LCT as the energy source $[9,10]$. However, as MCT are exclusively saturated fatty acids, an essential unsaturated fatty acid such as linoleic acid must be supplemented by blending with LCT for the nutritional requirement of the patients. Several investigators reported that a mixture of intravenously injected MCT/LCT was more advantageous as an energy source under seriously stressful conditions than LCT or glucose [11-13]. However, effects of enteral administration of MCT/LCT in sepsis have rarely been reported.

Recently, enteral nutrition was reported to be advantageous for patients with intestine dysfunction and immuno suppression [14-16]. We also reported beneficial effects of enteral diet containing fat as about $10 \%$ of total calories on septic rats [17]. In the present study, we investigated the efficacy of the enteral liquid diet containing 10\% MCT/LCT compared with one having LCT as fat on protein metabolism in septic rats, because the accelerated breakdown of body protein in sepsis can cause serious clinical problems [18].

\section{MATERIALS AND METHODS}

Animals. Six-week-old male Wistar rats were purchased from Charles River Japan, Inc. (Yokohama, Japan). They weighed about $250 \mathrm{~g}$ each, and were housed individually in a feeding room with a temperature of $23 \pm 2^{\circ} \mathrm{C}$ and a 12-h light/ 12-h dark cycle (light from 07:00 to 19:00). Each rat was given a commercial diet (CRF-1, Oriental Co., Tokyo) and tap water. The rats were randomly divided into 2 groups and were randomized by weight.

Preparation of the septic rats. The septic model with severe infection was prepared as shown in Fig. 1. After an 8-h fast, sepsis was induced by cecal ligation and puncture as described by Wichterman et al. [19]. Laparotomy was performed through a midline incision under pentobarbital anesthesia $(40 \mathrm{mg} / \mathrm{kg}$, i.p.). The cecum was filled with feces as a milky stool back from the ascending colon. After ligation of the cecum just below the ileocecal valve, the ligated part was punctured twice with an 18-gauge needle, the bowel was replaced in the peritoneal cavity, and the abdomen was closed with a two-layer suture. The postoperative rats received saline subcutaneously ( $5 \mathrm{ml} / 100 \mathrm{~g}$ body weight). Sixteen hours after the operation, the necrotic cecum was removed under anesthesia to permit recovery from the potentially lethal peritonitis and a catheter ( 5 Fr size umbilical catheter, Nippon 


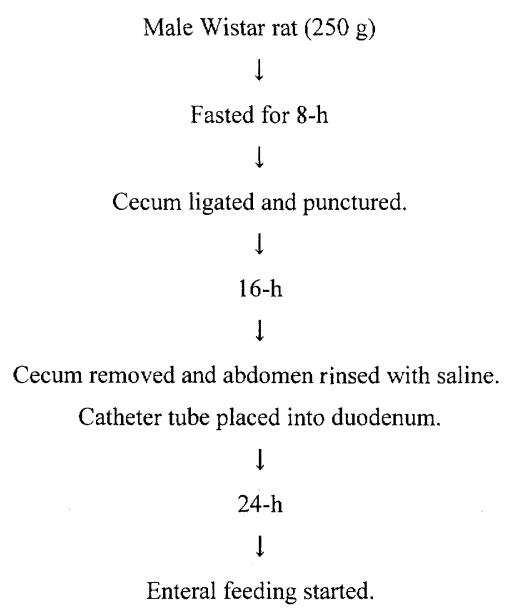

Fig. 1. Preparation of a septic model with severe infection in rats.

Sherwood Medical Ind., Tokyo) was inserted from the stomach into the duodenum for enteral feeding. The catheter was tunneled subcutaneously to exit the body at the back and was connected to a continuous infusion pump via a protected coil equipped with a swivel device. Each rat was starved for 24-h to simulate the initial recovery conditions of postoperative patients, who receive almost no food.

Diets and enteral feeding. The rats of each group were fed liquid diets containing either a mixture of MCT and LCT (MCT/LCT group) or LCT alone (LCT group). Both diets contained fat at $10 \%$ of the total calories. The compositions of the diets and of the fat are shown in Tables 1 and 2, respectively. The MCT/LCT diet was prepared by mixing MCT and safflower oil (both from Nissin Oil Mills, Ltd., Tokyo). Safflower oil was the supplement used to supply linoleic acid. Casein hydrolysis (average peptide length of 2.0, made by Snow Brand Milk Products Co., Ltd., Tokyo) was used as the nitrogen source (22\% total calories), and the total number of calories was adjusted to $100 \mathrm{kcal} / 100 \mathrm{ml}$ with dextrin. Each diet was supplemented daily with the same amount of a mixture of balanced electrolytes and vitamins.

Intraduodenal feeding was started at the level of $25 \mathrm{kcal} /$ day at 24 -h after surgery, the 1st postoperative day (POD). The calories were increased daily up to $75 \mathrm{kcal} /$ day at POD 5. Enteral feeding was continued until POD 6 (Table 3). No severe diarrhea was observed throughout the feeding period.

Protein metabolism and serum analyses. Body weights were measured daily at 10:00 am. Total urine and feces were collected for each animal every day. The daily nitrogen balance was calculated by subtracting the urinary and fecal nitrogen from the dietary nitrogen. For the measurement of urinary and fecal nitrogen, a semi-micro Kjeldahl method was used with a Kjeltec auto analyzer (MODEL 1030, Tecator, Sweden).

Vol. 22, No. 1, 1997 
Table 1. Composition of the experimental liquid diets (per $100 \mathrm{kcal}, 100 \mathrm{ml}$ ).

\begin{tabular}{|c|c|c|c|}
\hline & & MCT/LCT diet & LCT diet \\
\hline \\
\hline \multicolumn{2}{|c|}{ MCT oil $(\mathrm{g})$} & 0.7 & 0.0 \\
\hline LCT oil as & ifflower oil (g) & 0.4 & 1.1 \\
\hline \multicolumn{4}{|l|}{ Carbohydrate } \\
\hline \multicolumn{2}{|l|}{ Dextrin (g) } & 16.9 & 16.9 \\
\hline \multicolumn{4}{|l|}{ Protein } \\
\hline \multicolumn{2}{|c|}{ Casein peptides (g) } & 5.6 & 5.6 \\
\hline Electrolytes & \multicolumn{3}{|c|}{$\mathrm{Na} 74.9 \mathrm{mg}, \mathrm{K} 140.4 \mathrm{mg}$, Ca $52.1 \mathrm{mg}, \mathrm{Mg} 17.4 \mathrm{mg}$, P $59.9 \mathrm{mg}, \mathrm{C} 1127.0 \mathrm{mg}$} \\
\hline Vitamins & \multicolumn{3}{|c|}{$\begin{array}{l}\text { A } 232.4 \mathrm{IU}, \mathrm{B}_{1} 0.24 \mathrm{mg}, \mathrm{B}_{2} 0.27 \mathrm{mg}, \mathrm{B}_{6} 0.29 \mathrm{mg}, \mathrm{B}_{12} 0.37 \mu \mathrm{g}, \mathrm{C} 7.22 \mathrm{mg} \text {, } \\
\text { D } 15.2 \mathrm{IU}, \text { E } 0.8 \mathrm{IU}, \mathrm{K} .70 .9 \mathrm{mg}, \text { niacin } 2.94 \mathrm{mg} \text {, folic acid } 28.1 \mathrm{mg} \text {, } \\
\text { pantothenic acid } 0.42 \mathrm{mg} \text {, biotin } 4.6 \mu \mathrm{g}\end{array}$} \\
\hline Trace elements & \multicolumn{3}{|c|}{$\mathrm{Fe} 0.70 \mathrm{mg}, \mathrm{Zn} 1.06 \mathrm{mg}, \mathrm{Cu} 0.14 \mathrm{mg}$, Mn $0.18 \mathrm{mg}$} \\
\hline \multirow{2}{*}{\multicolumn{2}{|c|}{$\begin{array}{l}\text { \% of kcal from fat } \\
\% \text { of kcal from carbohydrate }\end{array}$}} & 10 & 10 \\
\hline & & 68 & 68 \\
\hline \multicolumn{2}{|c|}{$\%$ of kcal from protein } & 22 & 22 \\
\hline
\end{tabular}

MCT, medium-chain triglycerides; LCT, long-chain triglycerides.

Table 2. Fatty acid composition of fats in the experimental diets.

\begin{tabular}{llcc}
\hline \multirow{2}{*}{ Source } & \multicolumn{2}{c}{ Fatty acids } & \multicolumn{2}{c}{ Compositions (wt\%) } \\
\cline { 3 - 4 } & & MCT/LCT & LCT \\
\hline MCT & C 8:0 caprylic acid & 45.0 & - \\
Safflower oil & C10:0 capric acid & 15.0 & 0.0 \\
& C16:0 palmitic acid & 3.0 & 7.5 \\
& C18:0 stearic acid & 1.0 & 2.5 \\
& C18:1 oleic acid & 5.9 & 14.8 \\
& C18:2 linoleic acid & 29.7 & 74.2 \\
Total & C18:3 linolenic acid & 0.4 & 1.0 \\
\hline
\end{tabular}

Table 3. Schedule for enteral feeding of the experimental diets.

\begin{tabular}{lrrrrrr}
\hline & \multicolumn{7}{c}{ Days after operation } \\
\cline { 2 - 7 } & 25 & 2 & 3 & 4 & 5 & 6 \\
\hline $\begin{array}{c}\text { Energy administration } \\
\quad(\mathrm{kcal} / \text { day/rat) } \\
\begin{array}{c}\text { Protein administration } \\
\text { (g/day/rat) }\end{array}\end{array}$ & 1.4 & 2.0 & 2.5 & 3.6 & 4.2 & 4.2 \\
\hline
\end{tabular}

Immediately after the enteral feeding at the end of POD 6, the rats were anesthetized with pentobarbital and blood was drawn from the abdominal vein. The livers were removed, and their protein contents were measured according to Lowry et al. [20]. The serum was harvested and analyzed with an automatic serum analyzer (MODEL 7150, Hitachi, Ltd., Tokyo) for the following: albumin (bromocresol green method), total protein (Biuret method), triglycerides (free glycerol elimination method), non-esterified fatty acids (enzymatic method). 
Statistical analysis. The results were expressed as the mean \pm standard deviation of rats, 7 in the MCT/LCT diet group and 8 in the LCT diet group. The group means were compared by Student's $t$-test.

\section{RESULTS}

Body weight

Figure 2 shows the body weight of rats administered MCT/LCT or LCT in their diet. The mean body weight of each group decreased once to the minimum by POD 2 and then gradually recovered approximately to the starting level by POD 6. There was no significant difference between the two groups on any day.

\section{Nitrogen balance}

Figure 3 shows the daily nitrogen balance, an index of nitrogen retention in the body, during the postoperative period. The nitrogen balance in both groups was negative on POD 1, but it turned positive on POD 2 and remained so thereafter. After POD 3, the value for the MCT/LCT group tended to be higher than that for the LCT group. On POD 4, the value for the MCT/LCT group was significantly higher than that for the LCT group.

\section{Contents of liver protein}

The contents of liver protein, one of the major visceral protein, are shown in Fig. 4. The protein content per gram liver of the MCT/LCT group was significantly higher than that of the LCT group. Furthermore, the total liver protein content of the MCT/LCT group was higher than that of the LCT group, although the difference did not reach statistical significance.

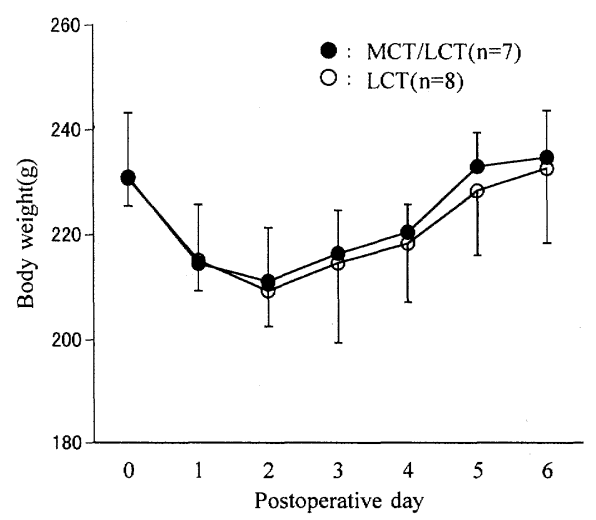

Fig. 2. Changes of body weights in septic rats on enteral feeding. Values are the mean \pm SD. 


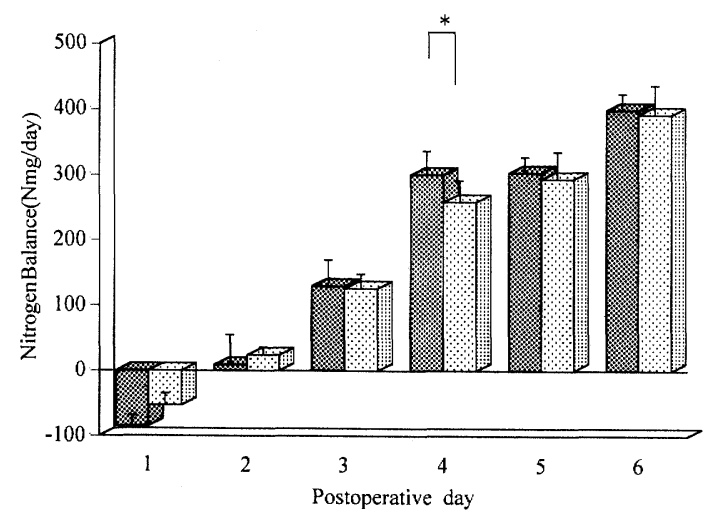

Fig. 3. Daily nitrogen balance in septic rats on enteral feeding. * Significantly different $(p<$ $0.05)$. Values are the mean $\pm \mathrm{SD}$.
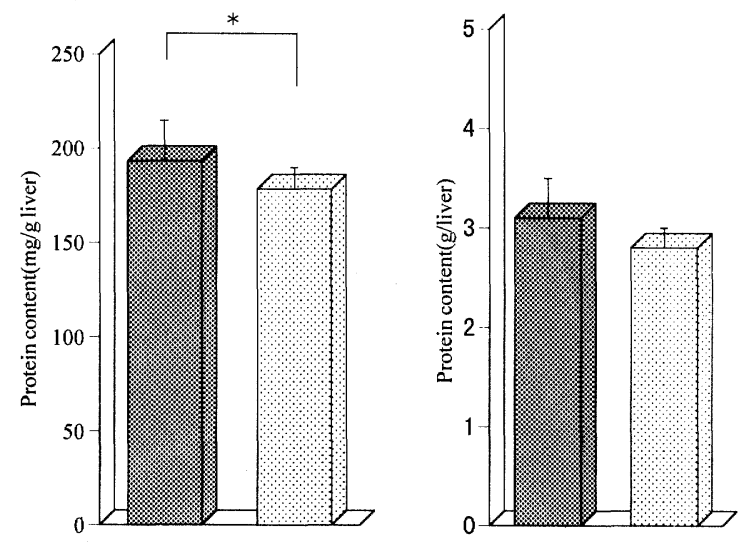

Fig. 4. Contents of liver protein in septic rats after 6 days of enteral feeding. *Significantly different $(p<0.05)$. Values are the mean \pm SD..$:$ MCT $/$ LCT $(n=7)$; 圆: LCT $(n=8)$.

\section{Concentrations of serum protein and lipid}

The concentrations of total protein and albumin in serum, important indices of protein metabolism and nutritional status in sepsis, are shown in Fig. 5. After 6 days of enteral feeding, serum total protein in the MCT/LCT group was significantly higher than the value for the LCT group. The concentration of serum albumin in the MCT/LCT group was also significantly higher than that in the LCT group.

Effects of the fat type on concentrations of serum triglycerides and nonesterified fatty acids are shown in Fig. 6. The serum triglycerides level of the MCT/ LCT group was significantly higher than that of the LCT group. Serum nonesterified fatty acid was notably higher in the MCT/LCT group than in the LCT group. 


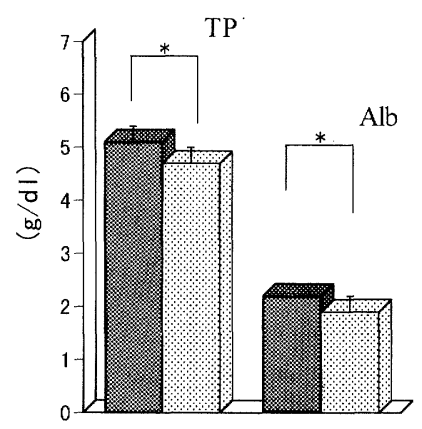

Fig. 5. Concentrations of serum total protein (TP) and albumin (Alb). ${ }^{*}$ Significantly different $(p<0.05)$. Values are the mean \pm SD. 圆: MCT $/$ LCT $(n=7)$; 圆: LCT $(n=8)$.
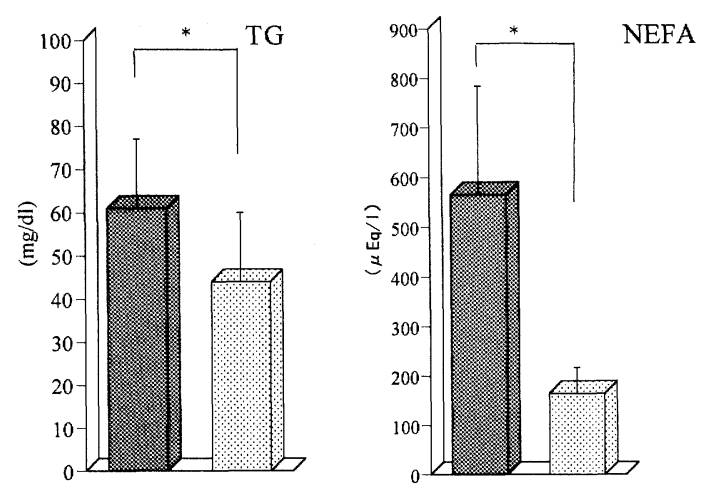

Fig. 6. Concentrations of serum triglycerides (TG) and non-esterified fatty acids (NEFA). ${ }^{*}$ Significantly different $(p<0.05)$. Values are the mean \pm SD. 圆: MCT $/$ LCT $(n=7)$; 橉: LCT $(n=8)$.

\section{DISCUSSION}

The most salient features of sepsis are the accelerated breakdown of muscle protein, the increase in nitrogen excretion, and the decrease in blood albumin concentration [18]. These phenomena ensure the degradation of body protein to supply energy. MCT are oxidized independently of carnitine, whereas LCT require carnitine to be oxidized. Jensen et al. [13] suggested that MCT would be a promising fat substrate for septic patients who were carnitine-depleted. As MCT were previously reported to be superior to LCT as an energy source in septic rats [21], in the present study we investigated the effect of MCT administration on protein metabolism in septic rats.

We used enteral diets that contained fat as $10 \%$ of total calories, because we previously had demonstrated this to be the preferable energy ratio of fat in septic rats based on nutritional status [17]. Regarding the mixture ratio of MCT and 
LCT, several investigators previously used ratios from $1: 1$ (MCT : LCT) to $7: 3$ in their studies on surgical nutrition [11-13]. We preferred the ratio of $6: 4$, a MCT-rich combination, as an intermediate ratio of previous studies.

The daily nitrogen balance in the MCT/LCT group shifted be higher than that in the LCT group after postoperative day 3; and at POD 4, the value for the MCT/LCT group was notably higher than that for the LCT group. In addition, the liver protein concentration was significantly higher in the MCT/LCT group than in the LCT one. These results indicate that nitrogen retention in the MCT/ LCT group was higher than that in the LCT group and that administration of $\mathrm{MCT} / \mathrm{LCT}$ may be preferable to LCT alone as a fat source for nitrogen retention in the septic rats. Eckart et al. [22] reported that the nitrogen balance with MCT/ LCT was higher than that with LCT in parenteral nutrition of intensive care patients. We suppose that the better nitrogen balance with MCT/LCT may be related to the rapid metabolism of MCT with production of non-esterified fatty acids and ketones as an energy source. An improved nitrogen balance has also been reported in injured rats receiving lipid containing MCT [23]. In the present study, the concentration of serum non-esterified fatty acids in the MCT/LCT group was significantly higher than that in the LCT group.

During enteral feeding, no severe diarrhea was observed in either group, and fecal weights did not significantly differ between them on any day (data not shown). These findings suggest that both types of fats were absorbed sufficiently under the tube-feeding condition. Therefore, it seems that the beneficial effects of MCT/LCT on protein metabolism in our enteral study were not dependent on the difference in absorption efficiency between MCT and LCT.

The concentrations of serum albumin and total protein in the MCT/LCT group were significantly higher than those in the LCT group, and they were positively related with the liver protein content. This suggests that the administration of MCT/LCT at a level of $10 \%$ of total calories might be adequate to promote protein synthesis in the liver of septic rats. In general, the non-esterified fatty acid concentration in blood decreases during sepsis in both man and experimental animals. Wannemacher et al. [24] reported that the decrease could be a consequence of an infection-induced decrease in plasma albumin, which is a fatty acid carrier. The albumin-bound free fatty acids are the single source of oxidizable fatty acid substrates for peripheral tissues [25]. In the present study, the MCT/LCT group with higher serum albumin concentrations also had higher serum nonesterified fatty acids, which are generated partly by hydrolysis of blood triglycerides. Thus, the administered MCT/LCT could provide fatty acids as an energy source for peripheral tissues more efficiently than LCT.

In conclusion, enteral administration of a MCT and LCT mixture as $10 \%$ of total calories may be advantageous to protein metabolism in septic rats compared with LCT alone. Our findings suggest that supplementation with MCT as a fat source in enteral nutrition might be preferable for septic patients. 


\section{REFERENCES}

1. Kudsk, K.A., Stone, J.M., Carpenter, G., and Sheldon, G.F. (1983): Enteral and parenteral feeding influences mortality after hemoglobin-E. J. Trauma, 23, 605-609.

2. Elwyn, D.H., Kinney, J.M., and Aokanazi, J. (1981): Energy expenditure in surgical patients. Surg. Clin. North Am., 61, 545-556.

3. Dunn, E.L., Moore, E.E., and Jones, T. (1981): Nutritional support of the critically ill patient. Surg. Gynecol. Obstet., 153, 45-48.

4. Chen, W.J. (1983): Utilization of exogenous fat emulsion in septic rats. J. Parenter. Enteral Nutr., 8, 14-17.

5. Niwa, H., Ogawa, Y., Kido, Y., Abe, Y., Kobayashi, M., Mori, T., and Tanaka, T. (1989): The rate of lipid oxidation in septic rat models. Jpn. J. Surg., 19, 439-445.

6. Nanni, G., Pittiruti, M., Giovannini, I., Boldrini, G., Ronconi, P., and Castagneto, M. (1985): Plasma carnitine levels and urinary carnitine excretion during sepsis. J. Parenter. Enteral Nutr., 9, 483-490.

7. Border, J.R., Burns, G.P., Rumph, C., and Schenk, W.G. (1970): Carnitine levels in severe infection and starvation, a possible key to prolonged abolic state. Surgery, 68, 175-179.

8. Bach, A.C., and Babayan, V.K. (1982): Medium-chain triglycerides, an update. Am. J. Clin. Nutr., 36, 950-962.

9. Birkhahn, R.H., and Border, J.R. (1981): Alternate or supplemental energy sources. $J$. Parenter. Enteral Nutr., 5, 24-31.

10. Dennison, A.R., Ball, M., Hands, L.J., Crowe, P.J., Watkins, R.M., and Kettlewell, M. (1988): Total parenteral nutrition using conventional and medium chain triglycerides. $J$. Parenter. Enteral Nutr., 12, 15-19.

11. Julius, U., and Leonhardt, W. (1988): Elimination and metabolism of a fat emulsion containing medium chain triglycerides. J. Parenter. Enteral Nutr., 12, 116-120.

12. Meraihi, Z., Lutz, O., Scheftel, J.M., Frey, A., and Bach, A.C. (1990): Gram-negative bacteria sepsis in the rat and tissue lipolytic activity on LCT and MCT/LCT-based commercial parenteral emulsions. Infusionstherapie, 17, 104-107.

13. Jensen, G.L., Mascioli, E.A., Seidner, D.L., and Bistrian, B.R. (1990): Parenteral infusion of long- and medium-chain triglycerides and reticuloendothelial system function in man. $J$. Parenter. Enteral Nutr., 14, 467-471.

14. Alexander, J.W., MacMillan, B.G., Stinnet, J.D., Ogle, C.K., and Bozian, R.C. (1980): Beneficial effects of aggressive protein feeding in severely burned children. Ann. Surg., 192, 505-517.

15. Moore, F.A., Feliciano, D.V., Andrassy, R.J., McArdle, A.H., Booth, F.V., MorgensteinWagner, T.B., Kellum, J.M., Jr., Welling, R.E., and Moore, E.E. (1992): Early enteral feeding, compared with parenteral, reduces postoperative septic complications. The results of a meta-analysis. Ann. Surg., 216, 172-183.

16. Kudsk, K.A., Croce, M.A., Fabian, T.C., Minard, G., Tolley, E.A., Poret, H.A., Kuhl, M.R., and Brown, R.O. (1992): Enteral versus parenteral feeding. Effects on septic morbidity after blunt and penetrating abdominal trauma. Ann. Surg., 215, 503-513.

17. Hayashi, N., Kashiwabara, N., Yoshihara, D., Takeshita, Y., Handa, H., Yanai, M., Maeda, J., and Yamakawa, M. (1995): Beneficial effects of enteral fat administration on liver dysfunction, liver lipid accumulation, and protein metabolism in septic rats. $J$. Nutr. Sci. Vitaminol., 41, 657-669.

18. O’Donnell, T.F., Clowes, G.H.A., Blackburn, G.L., Ryan, N.T., Benotti, P.N., and Miller, J.D.B. (1976): Proteolysis associated with a deficit of peripheral energy fuel substrates in septic man. Surgery, 80, 192-200.

19. Wichterman, K., Baue, A.E., and Chaudry, I.H. (1980): Sepsis and septic shock, a review of laboratory models and a proposal. J. Nutr. Res., 29, 189-201.

Vol. 22, No. 1, 1997 
20. Lowry, O.H., Rosebrough, N.J., Farr, A.L., and Randall, R.J. (1951): Protein measurement with the Folin phenol reagent. J. Biol. Chem., 193, 265-275.

21. Hayashi, N., Kashiwabara, N., Yanai, M., Kawanishi, G., and Yamakawa, M. (1989): Absorption and oxidation of medium-chain triglyceride and long-chain triglyceride in rats with peritonitis and effect of carnitine supplementation. Nippon Eiyo-Shokuryou Gakkaishi (J. Jpn. Soc. Nutr. Food Sci.), 42, 441-448 (in Japanese).

22. Eckart, J., Adolph, M., and Muhlen, U. (1980): Fat emulsion containing medium chain triglycerides in parenteral nutrition of intensive care patients. J. Parenter. Enteral Nutr., 4, 360-366.

23. Maiz, A., Yamazaki, K., Sobrado, J., Babayan, V.K., Moldawer, L.L., Bistrian, B.R., and Blackburn, G.L. (1984): Protein metabolism during total parenteral nutrition in injured rats using medium chain triglyceride. Metabolism, 33, 901-909.

24. Wannemacher, R.W., Pace, J.D., Beall, F.A., Dinterman, R.E., Petrella, V.J., and Neufeld, H.A. (1979): Role of the regulation of ketone body production during sepsis. J. Clin. Invest., 64, 1565-1572.

25. Spitzer, J.J., Bagby, G.J., Meszaros, K., and Lang, C.H. (1988): Alterations in lipid and carbohydrate metabolism in sepsis. J. Parenter. Enteral Nutr., 12, Suppl., 53S-58S. 